The Role of Identity Commitments in Depressive Symptoms and Stressful Life Events in Adolescence and Young Adulthood

\author{
Lotte van Doeselaar $^{\text {a, *, Theo A. Klimstra }}{ }^{\text {a }}$, Jaap J. A. Denissen ${ }^{\text {a }}$, Susan Branje ${ }^{\text {, }}$, \\ and Wim Meeus ${ }^{\mathrm{a}, \mathrm{b}}$
}
a Department of Developmental Psychology, Tilburg University, P.O. Box 90153, 5000 LE Tilburg, the Netherlands
${ }^{\mathrm{b}}$ Research Centre Adolescent Development, Utrecht University, P.O. Box 80140, 3508 TC Utrecht, the Netherlands

* Corresponding author.

E-mail address: lottevandoeselaar@gmail.com

\title{
Acknowledgement
}

This research was supported by several grants from the Netherlands Organization for Scientific Research (NWO) to Wim Meeus and Susan Branje, and an NWO Vidi grant (452-14-013) to Theo A. Klimstra.

This is the final author version (before journal's typesetting and copyediting) of the following paper: Van Doeselaar, L., Klimstra, T. A., Denissen, J. J. A., Branje, S., \& Meeus, W. (2018). The role of identity commitments in depressive symptoms and stressful life events in adolescence and young adulthood. Developmental Psychology, 54, 950-962. doi:10.1037/dev0000479

(C)American Psychological Association, 2017. This paper is not the copy of record and may not exactly replicate the authoritative document published in the APA journal. Please do not copy or cite without author's permission. The final article is available, upon publication, at: http://dx.doi.org/10.1037/dev0000479 


\begin{abstract}
The formation of a stable identity, consisting of a strong set of commitments, is a key developmental task in adolescence and young adulthood. Not resolving this task and lacking strong identity commitments is related to difficulties like depressive symptoms and stressful life events. However, the exact role of identity commitments in these negative experiences has remained unclear. In two longitudinal studies in the Netherlands spanning eight and six years, respectively, we examined the associations between career and interpersonal commitments, depressive symptoms, and the number of experienced stressful life events over time. Study 1 included 683 adolescents (11 to 15 years at T1) and 268 adolescents and young adults (16 to 20 years at T1). Study 2 included 960 adolescents (12 to 17 years at T1) and 944 young adults (18 to 24 years at T1). Both studies indicated that stronger identity commitments predicted relative decreases in negative experiences. In Study 2, stronger interpersonal commitments predicted relative decreases in depressive symptoms. In both studies, stronger career commitments predicted a relative decrease in stressful life events. Furthermore, only career commitments weakened after negative experiences. Interpersonal commitments did not weaken after negative experiences, possibly because of the importance of interpersonal relationships during difficult times. Moreover, identity commitments did not buffer the effect of stressful life events on depressive symptoms in either study. These findings underscore the importance of identity commitments in adolescence and young adulthood, but provide crucial nuances regarding their role in different life domains.
\end{abstract} Keywords: identity, commitment, depressive symptoms, stressful life events, negative events, longitudinal 
The Role of Identity Commitments in Depressive Symptoms and Stressful Life Events in Adolescence and Young Adulthood

Young people in Western societies are expected to make important choices in various life domains (Arnett, 2000; Erikson, 1968). They have to make several educational and occupational choices, and have to choose friends and a romantic partner. Young people's degree of commitment to these choices forms a central dimension of influential models on identity formation (Crocetti, Rubini, \& Meeus, 2008; Luyckx, Goossens, Soenens, \& Beyers, 2006; Marcia, 1966). Being strongly committed is defined as having made firm choices in identity-relevant domains, and identifying with these choices. If individuals strongly commit to their choices, the roles that come with these choices are part of their identity. Strongly committed individuals are therefore considered to have a more mature identity (Meeus, Van de Schoot, Keijsers, Schwartz, \& Branje, 2010). The formation of a stable identity consisting of a strong set of commitments - has been referred to as a key developmental task in adolescence and young adulthood (Arnett, 2000; Erikson, 1968).

Many young people are trying to establish a sense of continuity (Erikson, 1968). They are expected to define their own values, beliefs, and goals while retaining their identifications with parents (i.e., convictions directly adopted from their parents). Strong commitments can provide this sense of continuity, as well as a sense of meaning and direction in life.

Consequently, strong commitments may contribute to a more positive life course. In line with this, strong commitments tend to go together with various aspects of well-being (Meeus, 2011). However, evidence for concurrent associations does not yet provide much information on how commitments are linked to indicators of well-being during development.

Identity commitments might be linked to well-being in various ways (Klimstra \& Denissen, in press). For example, stronger identity commitments could be protective factors and predictive of higher well-being over time, or they may be a consequence of experiencing 
well-being. Findings of the few longitudinal studies that have been conducted indicate that stronger commitments are predictive of psychosocial adjustment (Crocetti, Branje, Rubini, Koot, \& Meeus, 2017; Luyckx, Soenens, Goossens, \& Vansteenkiste, 2007; Schwartz, Klimstra, Luyckx, Hale, \& Meeus, 2012; Van Doeselaar, Meeus, Koot, \& Branje, 2016), whereas less support was found for psychosocial adjustment predicting commitment strength (Schwartz et al., 2012). Because longitudinal studies on this are still scarce, more evidence is needed before it can be concluded that strong identity commitments are primarily a protective factor, predicting well-being, or whether they are a consequence of this.

To examine this, we focused on the link of identity commitments with two distinct but interrelated indicators of decreased well-being among young people: depressive symptoms and stressful life events. Young people with depressive symptoms feel down, experience less pleasure in activities, or have feelings of worthlessness (American Psychiatric Association, 2013). Depressive symptoms tap into a continuous construct with higher levels indicating the presence of more, or more severe, symptoms of depression. The degree to which young people experience depressive symptoms increases during adolescence, and peaks at the end of adolescence (Holsen \& Birkeland, 2017; Meeus, 2016). Young people’s depressive symptoms are bidirectionally associated with stressful life events. Stressful life events are undesirable events that impact individuals' lives as they require substantial readjustment (Holmes \& Rahe, 1967; Mueller, Edwards, \& Yarvis, 1977). Young people that are exposed to stressful life events have been found to experience an increase in depressive symptoms (i.e., the stress exposure effect), while young people who experience depressive symptoms over time experience more stressful life events (i.e., the stress generation effect; Cole, NolenHoeksema, Girgus, \& Paul, 2006; Liu \& Alloy, 2010; Pine, Cohen, Johnson, \& Brook, 2002). Although previous findings indicated that stronger commitments are negatively associated with depressive symptoms and stressful life events, only a few longitudinal studies 
have examined these associations across time (Anthis, 2002; Schwartz et al., 2012). In the present article, we assessed the link of young people's identity commitments with depressive symptoms and stressful life events across time in two longitudinal studies.

\section{Identity Domains}

Identity commitments are constructed in multiple identity-relevant domains. Many studies on identity commitment have aggregated these domains into one general commitment factor (Crocetti et al., 2008; Luyckx et al., 2006) or into two broad domains of ideological and interpersonal commitment (Grotevant \& Adams, 1984). In the present article, we take a slightly different approach by focusing on two more specific domains of personal identity: the career and interpersonal domain (e.g., Meeus, Iedema, Helsen, \& Vollebergh, 1999). These identity domains are highly salient for a vast majority of young people (Kroger, 1986; Skorikov \& Vondracek, 2011). In order to examine identity commitments' role across adolescence and young adulthood, we focused within each domain on two more specific life stage appropriate identity commitments. The career domain consisted of the commitment to education and work. In school, adolescents make their first important career identity choices. Later, these choices for a broad occupational field are expected to become more specific, when young adults choose a specific occupation. Because of the importance of educational choices for occupational possibilities, educational identity is expected to be a precursor of occupational identity. Indeed, educational and occupational identity formation are closely linked (Branje, Laninga-Wijnen, Yu, \& Meeus, 2014; Negru-Subtirica, Pop, \& Crocetti, 2017). Within the interpersonal identity domain, first introduced by Grotevant, Thorbecke, and Meyer (1982), we focused on the commitment to a best friend and romantic partner. During adolescence, friends become increasingly important (Brown, 2004), while romantic relationships increase in importance during young adulthood (Arnett, 2000).

\section{Identity Commitments and Depressive Symptoms}


By forming strong commitments, young people can acquire a sense of continuity and meaning in life (Erikson, 1968; Negru-Subtirica, Pop, Luyckx, Dezutter, \& Steger, 2016). According to existential psychologists (e.g., Frankl, 1985), lacking a sense of meaning can result in depressive symptoms. Having weak commitments can thus be emotionally troubling (Thoits, 1983). In adolescence and young adulthood, young people are expected to rethink their childhood identifications and become increasingly more independent from parents while figuring out potential future adult roles (Arnett, 2000; Erikson, 1968; Koepke \& Denissen, 2012). With adulthood nearing, it becomes increasingly urgent to figure out which adult roles to prepare for and commit to. As a result, inability to resolve the developmental task of identity formation might become increasingly stressful with age (Meeus et al., 1999). Therefore, weaker identity commitments were expected to be related to relative increases in depressive symptoms, and this effect was expected to become stronger with age from adolescence onwards.

Conversely, experiencing depressive symptoms could hinder identity formation. Establishing and maintaining strong identity commitments is an effortful process, in which individuals constantly form, evaluate, and revise their commitments (Crocetti et al., 2008; Luyckx et al., 2006). Côté (1996) stated in his identity capital model that cognitive abilities such as cognitive flexibility and critical thinking skills are necessary resources for this. However, depressive symptoms include a lack of energy, diminished cognitive abilities, and problems with decision-making (American Psychiatric Association, 2013). Moreover, depressive symptoms include a reduced interest in most activities. For young people who find almost nothing interesting, it might be harder to find people, an education, or a job to whom or which they would like to commit. Therefore, a higher degree of depressive symptoms could predict a weakening of commitments.

Likely, career commitments weaken more when experiencing depressive symptoms, 
compared to interpersonal commitments. Interpersonal relationships are highly important to individuals in times of distress (Ebata \& Moos, 1991; Updegraff \& Taylor, 2000). Therefore, interpersonal commitments might be more salient during stressful times compared to career commitments. During difficult times, the resources that individuals have left might thus primarily be used to maintain interpersonal commitments, rather than career commitments. This might result in relatively little change in the strength of interpersonal commitments, but a relative weakening of career commitments when experiencing depressive symptoms.

Previous cross-sectional studies confirmed a concurrent negative association between identity commitments and depressive symptoms (e.g., Crocetti et al., 2008; Luyckx et al., 2006; Luyckx, Klimstra, Duriez, Van Petegem, \& Beyers, 2013). This association was indeed stronger for commitments related to the career domain compared to the interpersonal domain (Clancy \& Dollinger, 1993; Helsen, Vollebergh, \& Meeus, 1999). In line with the idea that the importance of commitments increases during adolescence and young adulthood, some cross-sectional studies indicated that the association between commitment and depressive symptoms became stronger during adolescence and young adulthood (Luyckx et al., 2013; Meeus et al., 1999). Findings of a longitudinal study indicated that identity commitments have bidirectional negative associations with depressive symptoms in adolescence (Schwartz et al., 2012). To the best of our knowledge, no longitudinal study exists on how commitment and depressive symptoms relate to each other over time after adolescence.

\section{Identity Commitments and Stressful Life Events}

Not knowing what to commit to in life might not only be emotionally troubling, it could also result in a higher risk of experiencing stressful life events. Identity commitments can function as a compass in life, because they not only reflect who one is but also provide guidance in how to behave (Thoits, 1983). The roles to which young people commit often go with behavioral expectations and requirements. It has been argued that these requirements 
provide individuals with a sense of purpose and guidance. Individuals with stronger commitments to career goals and interpersonal relationships will invest in these commitments, by behaving in line with the achievement of career goals and strengthening of relationships (Roberts, O'Donnell, \& Robins, 2004). This might result in experiencing fewer negative career and interpersonal events (e.g., Klimstra et al., 2013). Moreover, lacking strong commitments and thus guidance might result in more random and risky behaviors and choices. Erikson (1968) already indicated that identity confusion could result in behaviors like running away, dropping out of school, quitting jobs, and staying out all night. In line with this, lacking strong commitments has been found to be associated with more hazardous and health-compromising behaviors (Schwartz et al., 2011). Consequently, stronger commitments could reduce the likelihood of experiencing stressful life events. Because commitments likely become more important during adolescence and young adulthood, we also expected commitments to become an increasingly stronger predictor of stressful life events with age.

Conversely, exposure to stressful life events might have a detrimental effect on the construction and maintenance of identity commitments. Stressful life events can constitute a reason to reassess the current life situation and present commitments (Grotevant, 1987). For example, someone experiencing the death of a family member might question their career path, because of the realization that life is short and that one should do what one likes most. Moreover, like depressive symptoms, the experience of stressful life events could compete with the resources that are needed to construct and adjust identity commitments (Côté, 1996). Stressful life events might directly result in loss of social or financial resources, and the accompanying stress and necessary coping could diminish individuals' cognitive resources. Consequently, exposure to stressful life events might result in a weakening of commitments. Like the association with depressive symptoms, interpersonal commitments might possibly weaken less after stressful life events, compared to career commitments, because of their 
importance in times of distress (Ebata \& Moos, 1991; Updegraff \& Taylor, 2000),

A few previous studies on adult samples have indicated that commitments might be affected by stressful life events. Findings of a retrospective study suggested that stressful life events mostly preceded a state of searching for a stable interpersonal and career identity (Kroger \& Green, 1996). In addition, a two-wave longitudinal study indicated that different categories of stressful life events had different effects on commitments. Specifically, healthrelated events had detrimental effects whereas family-related events had stimulating effects (Anthis, 2002). However, this study examined the relative change in commitment strength that took place after the occurrence of stressful life events. The baseline and follow-up measure of commitment both occurred after the year in which exposure to stressful life events took place. These previous findings could indicate that the strength of commitments reestablishes after the stressful period, or even then worsens. In the present studies, we examined whether commitment strength weakens relatively during the stressful period itself.

When examining associations between stressful life events and identity commitments, it is important to keep in mind whether certain stressful life events occur in the same domain as the commitment. For example, experiencing academic problems and becoming unemployed are directly related to individuals' careers. Individuals encountering stressful events are more or less forced to reevaluate their commitments in the respective domain. In addition, domain-specific commitments likely have a stronger predictive effect on stressful life events in the same domain (e.g., Klimstra et al., 2013). To examine whether stressful life events in general are linked to identity commitments, we checked whether a domain-specific commitment was also associated to stressful life events outside of this particular domain.

\section{Identity Commitments as a Buffer}

The role of identity commitments might go beyond simple associations with depressive symptoms and stressful life events over time. Although previous studies showed 
that bidirectional positive associations exist between young people's depressive symptoms and stressful life events (Cole et al., 2006; Liu \& Alloy, 2010; Pine et al., 2002), it is also assumed that individuals differ in their resilience to the stress exposure effect (Hankin \& Abramson, 2001). This is reflected in empirical findings, as not all studies found a strong or significant stress exposure effect (Compas, 1987). Stronger commitments might form a buffer against the stress exposure effect (Updegraff \& Taylor, 2000). Commitments could function as a compass in life during times of stress. Young people with stronger commitments might be better able to cope with stressful life events, as they have clearer goals to guide them.

The idea that stronger identity commitments make individuals less susceptible to developing depressive symptoms in times of stress has been suggested in previous studies. These studies focused on a specific stressful event (i.e., chronic illnesses; Luyckx et al., 2008) or on a specific identity domain not similarly salient to all groups of the general population (i.e., ethnic identity; Chavez-Korell \& Torres, 2014). In the present research, we focused on the possible buffering role of generally salient personal identity commitments including a broad range of stressful life events.

\section{The Present Studies}

In two longitudinal studies, we examined the hypotheses that: (1) stronger commitments are predictive of a relative decrease in depressive symptoms, (2) experiencing a higher level of depressive symptoms is associated with a relative weakening of commitments, (3) stronger commitments are predictive of experiencing relatively fewer stressful life events, (4) experiencing more stressful life events is associated with a relative weakening of commitments, and (5) having stronger commitments buffers against the effect of stressful life events on depressive symptoms. When examining these hypotheses, we controlled for the previously found bidirectional effects between stressful life events and depressive symptoms, and for associations with the other domain-specific commitment (e.g., predictions of 
depressive symptoms by interpersonal commitments were controlled for the prediction by career commitments). Regarding the different identity domains, we expected that (6) stressful life events and depressive symptoms would more strongly predict a relative weakening of career commitments than interpersonal commitments. With regard to age, we expected that (7) both commitments would be more strongly related to a relative decrease in depressive symptoms and stressful life events at the end of adolescence, compared to early adolescence.

We examined these hypotheses in two longitudinal studies, spanning eight and six years. These studies differ somewhat in their time intervals (four vs. three years), the specific life events included, and the time at which they were administered (2001-2009 vs. 19911997). Using two studies, we could test whether we could conceptually replicate our findings. Moreover, Study 2 builds on Study 1 by focusing not only on the period of adolescence, but also on young adulthood. Another strength of Study 2 is the use of a stressful life events measure that was likely more accurate compared to Study 1; Study 2 participants had to look back in time less far to report stressful events (i.e., up to 3 years) than in Study 1 (i.e., up to 8 years).

\section{Study 1}

\section{Method}

\section{Participants}

Data for Study 1 were drawn from the CONflict And Management Of RElationships project (CONAMORE). In this longitudinal project, 1,341 adolescents participated. We only used data from the first, fifth and sixth wave, referred from here on as Time 1 (T1), Time 2 (T2), and Time 3 (T3) respectively. These data were gathered in November to December 2001,2005 , and at the end of 2009 to the start of 2010 respectively. Participants reported on the experienced stressful life events at T3, using the Life History Calendar. For the current study, we selected the 951 participants who completed this measure. 
Selected participants did not differ significantly from unselected participants in career commitments, interpersonal commitments, or depressive symptoms at $\mathrm{T} 1, p \geq .050$. However, selected participants consisted of significantly more females $(56.2 \%$ vs. $40.3 \%), \chi^{2}(1)=$ $27.98, p<.001, \varphi=.14$, were slightly younger $\left(M_{\text {age }}=13.56\right.$ years, $S D=2.00$ vs. $M_{\text {age }}=$ 13.94 years, $S D=2.12), t(688)=3.03, p=.003, d=.18$, and identified themselves significantly more often as Dutch $(91.5 \%$ vs. $70.3 \%), \chi^{2}(4)=107.94, p<.001, \varphi=.29$. Within this selected sample, only $2.21 \%$ of the commitment and depressive symptoms measurements were missing across the three waves. Little's (1988) Missing Completely at Random (MCAR) test was not significant $\chi^{2}(106)=117.99, p=.201$, suggesting that these missing values occurred at random. Cases with missing data were included in Mplus 7 using Full Information Maximum Likelihood (FIML; Muthén \& Muthén, 1998-2015).

Participants were divided into two subsamples. The early-to-late adolescent subsample consisted of 683 adolescents (54.9\% females, $91.2 \%$ identified themselves as Dutch) aged 11 to 15 years at $\mathrm{T} 1\left(M_{\mathrm{age}}=12.36, S D=0.54\right)$. The middle adolescent-to-young adult subsample consisted of 268 participants (59.3\% females, $92.3 \%$ identified themselves as Dutch) aged 16 to 20 years at $\mathrm{T} 1\left(M_{\text {age }}=16.60, S D=0.75\right)$.

\section{Procedure}

Participants were recruited from high schools in the surroundings of Utrecht, the Netherlands. ${ }^{1}$ Before the start of the study, participants and their parents received a letter with information on the project and could provide written informed consent. More than $99 \%$ of the approached adolescents decided to participate. Adolescents completed the questionnaires at school after school hours or during home visits under supervision of trained assistants. The institutional review board of Utrecht University approved the CONAMORE project.

\footnotetext{
${ }^{1}$ Although participants were nested within schools at T1, no control for nesting across site was used because all participants changed their school at least once, between T1 and T3. Based on normative changes in the Dutch educational system, only in the early-to-late adolescent subsample two-thirds of the participants were expected to attend the same school at T2 as at T1. At T3, all participants were expected to have changed schools.
} 


\section{Measures}

Identity commitments. The Utrecht-Management of Identity Commitments Scale (U-MICS) was used to assess commitments to education, work, friends, and romantic partners. Each commitment was measured with five items (e.g., "my education/work/best friend/partner gives me certainty in life"), answered on a 5-point scale ranging from 1 (completely true) to 5 (completely untrue). Scores were recoded, with higher scores reflecting stronger commitments. A previous study by Crocetti et al. (2008) showed support for the construct validity of the U-MICS. In our study, Cronbach's alphas ranged from .83 to .97 across waves and subsamples. Interpersonal commitment consisted of the average commitment to a friend and/or romantic partner. Career commitment consisted of the average commitment to education and/or work. Whether participants reported on a domain-specific commitment depended on the applicability (e.g., having a romantic partner or not). Because almost no adolescents had a job at T1, work commitment was only assessed at T2 and T3.

Depressive symptoms. The Children's Depression Inventory (CDI; Kovacs, 1985) was used to assess depressive symptoms. This self-report questionnaire consists of 27 items (e.g., "I am sad all the time"), answered on a 3-point scale: 1 (false), 2 (a bit true), and 3 (very true). Previous studies indicate the CDI has sufficient construct validity (Roelofs et al., 2010). Cronbach's alphas ranged from .88 to .94 across waves and subsamples.

Stressful life events. Stressful life events were assessed at T3 with the Life History Calendar (Caspi et al., 1996) adapted by Meeus (2009). Participants indicated whether and when they had experienced several events since they were 12 years old. Consequently, data on stressful life events that had occurred during the study were available for all participants. From the Life History Calendar we selected events that were previously judged to be stressful for young people (Lüdtke, Roberts, Trautwein, \& Nagy, 2011; Swearingen \& Cohen, 1985). We focused on generally stressful events, as we were interested in the objective occurrence of 
events, and including participants' judgements on the impact of events could be confounded with the measure of depressive symptoms (Mueller et al., 1977). The following events were included: breakup with a romantic partner, academic problems (i.e., repeating a grade, going to a lower educational level, and ending education without a diploma), becoming unable to work, becoming unemployed, becoming physically ill or wounded, being the victim of a crime, and experiencing the death of someone close (i.e., a family member or intimate friend). For events that took place in November or December 2001 or 2005, or that took place in 2001 or 2005 but for which no month was specified, it was unclear whether these had happened before or after T1 and T2. Therefore, these events were excluded (4.34\% of events). For all participants we computed the frequency of events that had taken place between $\mathrm{T} 1$ and $\mathrm{T} 2$, and between $\mathrm{T} 2$ and $\mathrm{T} 3$.

\section{Strategy of Analysis}

The hypotheses were examined with a structural equation model in Mplus 7 (Muthén \& Muthén, 1998-2015). The model consisted of the following parameters (see Supplemental Figure 1): (a) 4-year stability paths for career commitment, interpersonal commitment, stressful life events, and depressive symptoms, (b) cross-lagged effects between career commitment, interpersonal commitment, stressful life events, and depressive symptoms, (c) interaction terms between career commitment and stressful life events and between interpersonal commitment and stressful life events predicting depressive symptoms, (d) concurrent correlations between career commitment, interpersonal commitment, and depressive symptoms at T1, (e) concurrent correlations between the residuals of career commitment, interpersonal commitment, and depressive symptoms at T2 and T3. These latter correlations reflect associations between relative changes and will thus be referred to as correlated relative changes from here on. The model was tested and evaluated according to conventional procedures and norms (for details see online supplemental material). 


\section{Results and Discussion}

\section{Descriptive Analyses}

Descriptive statistics and relative stability of the variables of interest are shown in Supplemental Table 1. Career commitment was not significantly stable across T1 and T2 in the middle adolescent-to-young adult subsample. Likely, this was due to the change in measurement focus from education to work. During the four years between waves, most participants (62.2\% to $88.9 \%$ across waves and subsamples) experienced at least one stressful life event. Supplemental Table 2 shows the correlations between the variables of interest.

\section{Longitudinal Model}

Time invariance and model fit. Time invariance tests showed that each cross-lagged effect, correlated relative change, and interaction effect could be constrained to be time invariant without significantly reducing the model fit, $\triangle$ RMSEAs $=-.001-.002, \Delta$ CFIs $=-$ $.005-.001, p \mathrm{~s}$ of $\Delta \chi^{2} \mathrm{SB} \geq .038$. This time invariant model had a good fit, $\chi^{2}{ }_{\mathrm{SB}}(57)=71.35, p$ $=.096, \mathrm{CFI}=.98, \mathrm{RMSEA}=.02,90 \% \mathrm{CI}$ of RMSEA $[.000, .027]$. The significant parameter estimates are shown in Figure 1. A full overview of the results is available in Supplemental Table 3.

Identity commitments and depressive symptoms. Our findings showed that commitments' strength did not predict a relative change in depressive symptoms four years later. Using a multi-group analysis we tested whether the cross-lagged effects of both commitments on depressive symptoms were stronger in the older (middle adolescent-toyoung adult) subsample than in the younger (early-to-late adolescent) subsample. In contrast to our hypothesis, the cross-lagged effects could be constrained to be equal across subsamples without worsening the model fit significantly: interpersonal commitment, $\triangle \mathrm{RMSEA}=.001$, $\Delta \mathrm{CFI}=-.002, \Delta \chi^{2} \mathrm{SB}(1)=3.27, p=.071$, career commitment, $\Delta \mathrm{RMSEA}=.000, \Delta \mathrm{CFI}=.000$, $\Delta \chi^{2} \mathrm{SB}(1)=0.76, p=.385$. 
The reversed cross-lagged effects showed that higher levels of depressive symptoms were significantly associated with a relative weakening over time of career commitment, but not interpersonal commitment. Although the confidence intervals of the effects from depressive symptoms to career commitment and from depressive symptoms to interpersonal commitments overlapped, the overlap on one side of the confidence interval (i.e., one confidence interval "arm") was less than 50\%: $28 \%$ for the T1 to T2 effects, and $36 \%$ for the T2 to T3 effects (Cumming, 2009). This suggests that the cross-lagged effects of depressive symptoms predicting a weakening of career commitment, 95\% CIs T1-T2 [-.13, -.03] and T2$\mathrm{T} 3[-.10,-.02]$, were stronger than the non-significant cross-lagged effects on interpersonal commitment, 95\% CIs T1-T2 [-.04, .06] and T2-T3 [-.04, .05], $p<.05$, as expected. Furthermore, a relative strengthening in interpersonal and career commitments was associated with a relative decrease of depressive symptoms.

Identity commitments and stressful life events. The cross-lagged effect of career commitment on stressful life events was significant. Stronger career commitments were associated with a relative decrease in stressful life events. This effect appeared to be generalizable to events beyond stressful career events because it remained significant and of similar strength when excluding the stressful life events directly associated with individuals' careers (i.e., having academic problems, becoming unemployed, and becoming unable to work), $\beta=-.10, p=.006$. The cross-lagged effect of interpersonal commitment on stressful life events was not significant. A multi-group analysis showed that the cross-lagged effects of both types of commitments on stressful life events could be constrained to be equal between the early-to-late adolescent and middle adolescent-to-young adult subsamples without worsening the model fit significantly: interpersonal commitment, $\triangle \mathrm{RMSEA}=.001, \Delta \mathrm{CFI}=$ $.002, \Delta \chi^{2} \mathrm{SB}(1)=2.73, p=.099$, career commitment, $\Delta \mathrm{RMSEA}=.000, \Delta \mathrm{CFI}=.001, \Delta \chi^{2} \mathrm{SB}(1)$ $=0.14, p=.712$. As for the cross-lagged effect of commitments on depressive symptoms, this 
finding indicates that during adolescence commitments did not become a stronger predictor.

The reversed cross-lagged effects of experiencing stressful life events on a relative changes in interpersonal and career commitment were not significant. Commitments did not weaken relatively during a period of many experienced stressful life events.

Identity commitments as a buffer. Lastly, we tested whether commitments buffered against the effect of stressful life events on depressive symptoms. Although depressive symptoms predicted a relative increase in stressful life events, the reversed exposure effect was not significant. The interaction terms referring to a possible buffering effect of commitments were also not significant.

\section{Summary of Findings}

Across four-year timespans, stronger identity commitments were predictive of experiencing relatively less stressful life events, while depressive symptoms predicted a relative weakening of commitments. These associations only appeared for career commitments, and not for interpersonal commitments. There was no evidence for a buffering role of commitments or an increase in the strength of identity commitments' predictive role across adolescence.

\section{Study 2}

In Study 2, we examined whether we could conceptually replicate Study 1's findings, using slightly different measures and a three-year interval. Study 2 was already performed in the 1990s, yet this study did not suffer from some limitations of Study 1. In Study 2, individuals reported the stressful life events they had experienced in the last three years at each wave. This is likely a more accurate measure than the measure of Study 1, in which participants recalled stressful life events only at the end of the study (Raphael, Cloitre, \& Dohrenwend, 1991). The use of this potentially more accurate measure might produce support for the exposure effect of stressful life events on commitments and depressive 
symptoms, as well as for the buffering role of commitments in this latter exposure effect.

Furthermore, Study 2 consisted of a sample with a larger age range, compared to Study 1 . This was important because we expected that commitments would become more influential with age across adolescence and young adulthood (Erikson, 1968; Luyckx et al., 2013; Meeus et al., 1999). In Study 1, no evidence for age differences in the predictive effects of commitments on depressive symptoms and stressful life events was found. However, in Study 1, most participants had only entered young adulthood at the last wave, as the early-tolate adolescent subsample was on average 20 years of age at the last wave and the middle adolescent-to-young adult subsample was on average 24 years by then. In Study 2, we examined our hypotheses in a sample that consisted of adolescents and young adults (with ages up to 24 years) at baseline. This expanded age range might produce evidence for the expected age differences in the predictive effect of commitments.

\section{Method}

\section{Participants}

Data were derived from the longitudinal Utrecht Study of Adolescent Development (USAD) 1991 - 1997 (Meeus \& 't Hart, 1993). For this project, a sample of adolescents and young adults aged 12 to 24 years and their families was recruited from an existing panel of 10,000 households. Of the approached families, $73.9 \%$ decided to participate. This sample was representative of the native Dutch adolescent population of the early 1990s ('t Hart, 1992). Data were gathered with a three-year interval in 1991, 1994, and 1997, in this study referred to as T1, T2, and T3, respectively. At T1, a sample of 3,393 adolescents and young adults participated (99.2\% identified themselves as Dutch). A selection of 1,966 and 1,307 individuals participated in the longitudinal project at T2 and T3, respectively. Participants initially provided their consent for the longitudinal part of the study, but about $24 \%$ of the participants later refused to participate at T2 or T3. Little's (1988) MCAR test was significant 
$\chi^{2}(12,991)=15,330.81, p<.001$, but the normed $\chi^{2}\left(\chi^{2} / d f\right)$ of 1.18 indicated that the items had a random pattern of missingness (Bollen, 2014). For each variable, missing items were imputed with the expectation maximization (EM) algorithm in case an individual reported on at least $66 \%$ of the items of that particular variable. If an individual reported on less than $66 \%$ of the items of a variable, this variable was judged as missing and not imputed.

For the present study, we selected the 1,904 participants (56.7\% females) who had (potentially imputed) scores on at least half of the variables of interest on at least two of the three measurement waves. These participants were on average 18.26 years old $(S D=3.76)$ at T1. We distinguished two subsamples: a group of 960 adolescents (12 to 17 years at T1, $M_{\text {age }}$ $=15.04, S D=1.66,55.5 \%$ females ) and a group of 944 young adults ( 18 to 24 years at $\mathrm{T} 1$, $M_{\text {age }}=21.54, S D=2.08,57.8 \%$ females). Selected participants were somewhat younger, compared to unselected participants $\left(M_{\text {age }}=19.43\right.$ years, $\left.S D=3.47\right), t(3298)=9.33, p<.001$, $d=0.32$, and consisted of significantly more females, compared to unselected participants (48.3\%), $\chi^{2}(1)=22.78, p<.001, \varphi=.08$. At $\mathrm{T} 1$, the selected participants reported significantly fewer stressful life events, $t(2986)=4.058, p<.001, d=0.14$, and had slightly weaker interpersonal commitments, $t(3033)=2.01, p=.044, d=0.07$. These groups did not differ significantly in career commitments or depressive symptoms at T1, $p \geq .076$. Although selected participants differed from unselected participants, differences were rather small and unlikely to substantially influence our results. Within the selected sample, $13.51 \%$ of the variables were missing. Little's (1988) MCAR test, $\chi^{2}(655)=841.78, p<.001, \chi^{2}\left(\chi^{2} / d f\right)=$ 1.29, indicated that the variables were missing at random (Bollen, 2014). We retained cases with missing data in Mplus 7, using FIML (Muthén \& Muthén, 1998-2015).

\section{Procedure}

At each wave, participants and their parents provided active informed consent. Next, participants completed, amongst others, the questionnaire measuring stressful life events at 
home in the presence of a trained assistant. Afterwards, participants were requested to fill out other questionnaires on their own, including the measures on depressive symptoms and identity commitments, and send them to the research organization within a week. The study was not reviewed by any research ethics committee, but was approved by the Netherlands Organisation for Scientific Research in 1990 and conducted in accordance with the APA ethical standards (American Psychological Association, 2010).

\section{Measures}

Identity commitments. The Utrecht-Groningen Identity Development Scale (UGIDS; Meeus, 1996) was used to measure the commitments to education, work, a best friend, and a romantic partner. The U-GIDS is highly similar to the newer version of this measure (i.e., U-MICS), used in Study 1. Depending on participants' age (i.e., 12 to 14 years, or 15 years and older), two slightly different versions of the U-GIDS were used. We used the five items that were included in both versions of the U-GIDS, as well as in Study 1's measure. In contrast to Study 1, all participants reported on one of the interpersonal commitments (i.e., to their best friend or romantic partner) and one of the career commitments (i.e., to their education or work). Participants aged 12 to 14 years were asked to report on the commitment to their best friend and their education. Participants aged 15 years and older reported on the peer (best friend or romantic partner) that was most important to them, and on the commitment to their education or work depending on the applicability. Our variable interpersonal commitment consisted of participants' commitment to a best friend or romantic partner. Career commitment consisted of participants' commitment to education or work. Cronbach's alphas ranged from .85 to .90 across waves and subsamples.

Depressive symptoms. A subscale of a shortened version of the General Health Questionnaire (GHQ; Goldberg, 1978) was used to measure depressive symptoms during the past four weeks. This subscale consisted of four items (e.g., "feeling unhappy and dejected"), 
which could be answered on a 4-point scale ranging from 1 (not at all) to 4 (much more than usual). Cronbach's alphas ranged from .82 to .85 across waves and subsamples.

Stressful life events. Stressful life events were assessed by asking participants to indicate if they had experienced a list of events during the past three years. From this list, we selected events that were previously judged to be stressful for young people (Lüdtke et al., 2011; Swearingen \& Cohen, 1985). The following events were included: becoming unemployed or unable to work, being the victim of a serious crime (i.e., robbery, theft, or rape), having financial difficulties, experiencing a major accident, being severely ill, being expelled from school, the death of a close friend, the death of a parent, the death of a grandparent, severe illness of a parent, severe illness of someone close, a major accident of someone close, parental divorce, a suicide (attempt) of someone close, and the breakup of a romantic relationship. For all participants a frequency score was computed that represented the number of stressful life events experienced in the three years before each wave.

\section{Strategy of Analysis}

The model and analyses in Study 2 were similar to those of Study 1 . The only difference was the inclusion of stressful life events that occurred before T1, which was not included in Study 1. Because of this included variable, the cross-lagged effects predicting stressful life events between T1 and T2 now represent a prediction of relative change.

\section{Results and Discussion}

\section{Descriptive Analyses}

Descriptive statistics and relative stability of the variables of interest are displayed in Supplemental Table 4. In the three years before each wave, most participants experienced at least one stressful life events (69.9\% to $81.4 \%$ across waves and subsamples). Supplemental Table 5 shows the correlations between the variables of interest.

\section{Longitudinal Model}


Time invariance and model fit. All cross-lagged effects, correlated relative changes, and interaction effects could be constrained to be time invariant without significantly worsening the model fit, $\Delta \mathrm{RMSEAs}=.000, \Delta \mathrm{CFIs}=-.002-.000, p \mathrm{~s}$ of $\Delta \chi^{2} \mathrm{SB} \geq .021$. This resulted in an acceptable model fit, $\chi^{2} \mathrm{SB}(79)=182.68, p<.001, \mathrm{CFI}=.94, \mathrm{RMSEA}=.03$, 90\% CI of RMSEA [.021, .031]. Figure 2 shows the significant parameter estimates of this time invariant model. A full overview of the results is available in Supplemental Table 3.

Identity commitments and depressive symptoms. The cross-lagged effects of commitments on depressive symptoms showed that stronger interpersonal commitments were associated with a small relative decrease in depressive symptoms. For career commitment this effect was not significant. A multi-group analysis showed that the cross-lagged effects of interpersonal as well as career commitment predicting relative changes in depressive symptoms could be constrained to be equal between the adolescent and young adult subsamples: interpersonal commitment, $\Delta \mathrm{RMSEA}=-.001, \Delta \mathrm{CFI}=.000, \Delta \chi^{2} \mathrm{SB}(1)=0.91, p=$ .339 , career commitment, $\Delta \mathrm{RMSEA}=.000, \Delta \mathrm{CFI}=-.002, \Delta \chi^{2} \mathrm{SB}(1)=5.29, p=.021$. This showed that the predictive effect of commitments was not stronger in the older subsample.

The reversed cross-lagged effects of depressive symptoms on career and interpersonal commitment were not significant. ${ }^{2}$ Relative changes in interpersonal and career commitments were significantly negatively associated with relative changes in depressive symptoms.

Identity commitments and stressful life events. Significant cross-lagged effects showed that a stronger career commitment was related to a relative decrease in stressful life events. This effect remained significant and of similar strength when excluding events directly related to individuals' careers (i.e., becoming expelled from school, and becoming unemployed or unable to work), $\beta \mathrm{s}=-.04, p=.028$. The cross-lagged effects of interpersonal

\footnotetext{
${ }^{2}$ Removing the cross-lagged effects of stressful life events on interpersonal and career commitments from the model, resulted in significant negative cross-lagged effects of depressive symptoms on career commitments, $\beta \mathrm{s}=-.04, p \mathrm{~s}=.034$, but not on interpersonal commitments, $\beta \mathrm{s}=.03, p \mathrm{~s}=.108$.
} 
commitment on stressful life events were not significant, however. A multi-group analysis showed that both cross-lagged effects could be constrained to be equal between the adolescent and young adult subsample without reducing the model fit significantly: interpersonal commitment, $\Delta \mathrm{RMSEA}=.000, \Delta \mathrm{CFI}=.000, \Delta \chi^{2} \mathrm{SB}(1)=1.63, p=.202$, career commitment, $\Delta \mathrm{RMSEA}=.000, \Delta \mathrm{CFI}=-.001, \Delta \chi^{2} \mathrm{SB}(1)=3.36, p=.067$. This contradicts the hypothesis that the predictive effect of commitments' strength increases with age.

The reversed cross-lagged effects showed that experiencing more stressful life events was associated with a relative weakening of career commitment. This effect remained significant and of similar strength when excluding the stressful life events directly related to careers, $\beta \mathrm{s}=-.08, p<.001$. Stressful life events did not predict changes in interpersonal commitment strength. The confidence intervals of the cross-lagged effects predicting a weakening in career commitment, 95\% CIs T1-T2 [-.13, -.06] and T2-T3 [-.14, -.07], did not overlap with those of the non-significant cross-lagged effects on interpersonal commitment 95\% CIs T1-T2, [-.03, .03] and T2-T3 [-.04, .03]. As expected, stressful life events were thus significantly stronger associated with a relative weakening in career commitments, compared to interpersonal commitment $(p<.01$; Cumming, 2009).

Identity commitments as a buffer. Stressful life events and depressive symptoms were significantly bidirectionally positively associated over time. However, commitment strength did not moderate the effect of stressful life events on depressive symptoms, because none of the interaction effects were significant.

\section{Summary of Findings}

In Study 2, we conceptually replicated several of the findings of Study 1. Again, stronger career commitments predicted experiencing relatively less stressful life events over time. In addition, career commitment was again the only domain-specific commitment that weakened relatively after negative experiences, although this time after experiencing stressful 
life events instead of depressive symptoms. Like in Study 1, Study 2's findings did not show evidence for a buffering role of commitments or an increase in the strength of commitments' predictive effect with age. Unlike in Study 1, the results of Study 2 showed that stronger interpersonal commitments predicted a small relative decrease of depressive symptoms.

\section{General Discussion}

The main goal of the two longitudinal studies was to investigate the role of young people's career and interpersonal identity commitments in the experience of depressive symptoms and stressful life events. Overall, our findings indicate that identity commitments predict depressive symptoms and stressful life events, but are also predicted by these negative experiences. However, the strength of evidence varied per hypothesis.

\section{Identity Commitments and Depressive Symptoms}

Young people's strength of identity commitments was expected to be negatively related to depressive symptoms over time. Evidence for this was repeatedly shown in the associated relative changes. Across studies, a relative strengthening of career and interpersonal commitments correlated with a relative decrease in depressive symptoms. Regarding the direction of effects, Study 2's findings showed that stronger interpersonal identity commitments predicted a relative decrease in depressive symptoms three years later, even after controlling for exposure to stressful life events. This finding is in line with the idea that not having constructed strong commitments is emotionally troubling (Thoits, 1983), possibly because this coincides with a lack of meaning and purpose in life (Frankl, 1985). It is also in line with a one-year interval study by Schwartz et al. (2012) on this association in adolescence. However, in Study 1, stronger commitments were not predictive of relative decreases in depressive symptoms four years later. The current and previous findings suggest that weak commitments put individuals at risk for distress across a relatively long period (i.e., one to three years), but that these effects might wear out at some point (i.e., four years). This 
could especially apply to the periods of adolescence and young adulthood, since this is when identity is primarily expected to develop (Arnett, 2000; Erikson, 1968). Therefore, weak commitments might only have limited predictive power across time.

Furthermore, we expected that experiencing depressive symptoms, which can involve diminished cognitive abilities and interests (Côté, 1996), would predict a relative weakening of commitments. We found inconsistent support for this expectation, as such an association was only found in Study 1 for career commitment. This lack of strong support seems not in line with findings by Schwartz et al. (2012), which indicated bidirectional associations between general identity commitments and depressive symptoms in adolescence across oneyear intervals. The difference in findings is likely explained by the fact that we controlled for the predictive effect of stressful life events on commitments. Without stressful life events as a control variable, depressive symptoms did predict a relative weakening of career commitments in Study 2 (see Footnote 2). Possibly, both types of negative experiences overlap in their prediction of commitment strength, because they both compete with the resources that are needed to construct and adjust identity commitments (Côté, 1996).

\section{Identity Commitments and Stressful Life Events}

A highly consistent finding was that young people with stronger career commitments experienced relatively less stressful life events over time. This result appeared in both studies, after controlling for the influence of depressive symptoms on stressful life events. Moreover, in both studies this finding was generalizable to events beyond stressful career related events. The mechanism behind this novel finding could be that identity commitments function as a compass guiding the behavior of young people (Erikson, 1968; Roberts et al., 2004; Thoits, 1983). Young people with stronger career commitments likely behave in function of the achievement of career goals, resulting in less random and risky behaviors and choices.

Conversely, exposure to stressful life events did not consistently predict relative 
changes in identity commitments across the two studies. Only in Study 2, exposure to stressful life events predicted a relative weakening of career commitment. One possible explanation for this difference in findings is that the measures of stressful life events were different across Study 1 and 2. Because of the longer period on which participants had to reflect in Study 1 (i.e., eight years compared to three years in Study 2), it might have been harder to indicate accurately whether and when events had occurred (Raphael et al., 1991). However, even across the last four years of Study 1 stressful life events were not predictive, while the influence on accuracy of recalling for this period is likely comparable to Study 2. Our inconsistent findings could therefore also indicate that the exposure effect of stressful life events on commitments is not that strong in every individual. Perhaps, such effects can be buffered by other factors like support of friends or family, which can differ in prevalence between samples.

\section{Identity Commitments as a Buffer}

Although we found support for the anticipated effect of depressive symptoms on stressful life events in both studies, we found inconsistent support for the reversed effect of stressful life events on depressive symptoms (Cole et al., 2006; Liu \& Alloy, 2010; Pine et al., 2002). Like the effect of stressful life events on career commitments, this inconsistency could be a result of the measure of stressful life events in Study 1 or be caused by buffer factors. However, neither of our studies showed evidence for a buffer effect of commitments in the effect of stressful life events on depressive symptoms.

Apparently, being more strongly committed to identity choices is not enough to be resilient in stressful times. Perhaps this is caused by the variation in the content of the commitments, which might affect their adaptiveness (Klimstra \& Denissen, in press). For example, being strongly committed to a job that is experienced as highly stressful is likely not protective. Furthermore, commitments are a key component of influential models on identity 
formation, but the degree to which commitments are being explored and reconsidered is also important (Crocetti et al., 2008). Perhaps strong commitments do protect against developing depressive symptoms after exposure to stressful life events, but only if they have been thoroughly explored and are not being reconsidered. Such an identity formation profile can be captured by the identity status approach (Marcia, 1966; Meeus et al., 2010). Focusing on the content of commitments and on the combination with other identity dimensions might be valuable approaches for future research on the buffering role of identity.

\section{Identity Domains}

Although depressive symptoms and stressful life events did not consistently predict a relative weakening of one domain-specific identity commitment across studies, the career domain was the only domain that relatively weakened after these difficult experiences. That is, relative changes in interpersonal commitment strength were not predicted by depressive symptoms or stressful life events. Accordingly, previous findings indicate that internalizing symptoms are more strongly associated with commitments related to the career domain than with commitments related to the interpersonal domain (Clancy \& Dollinger, 1993; Helsen et al., 1999). The current findings suggest that this difference may be caused by career commitments becoming relatively weaker following negative experiences, while interpersonal commitments remain relatively stable. During and after stress, young people might perceive their interpersonal relationships as increasingly important. They might turn to others for support (Ebata \& Moos, 1991). In addition, having a supportive peer to rely on in times of distress could increase their appreciation of and commitment to this relationship (Updegraff \& Taylor, 2000). Thus, interpersonal identity might be generally more salient to young people in distress than career identity. Therefore, a depletion of resources might be more harmful to career commitments, as remaining resources would be invested in the more salient interpersonal commitments, to the detriment of career commitments. 
Although we had no hypothesis about a difference between the two identity domains' predictive power, career commitment was in both studies significantly related to a relative decrease in stressful life events while interpersonal commitment was not. A probable explanation for this could be that an interpersonal commitment can also entail committing to peers who take many risks (e.g., someone who uses drugs, drinks a lot of alcohol, or drives under influence). Committing to a risk-taking peer might result in more stressful events happening to a peer, and can increase young people's own risk behavior (Cohen \& Prinstein, 2006). Because of the greater potential heterogeneity in effects that peers may exert relative to the career domain, interpersonal commitments in general could be less predictive of stressful life events than career commitments.

\section{Identity Commitments in Adolescence and Young Adulthood}

A final hypothesis was that identity commitments would become more influential with age, because it becomes increasingly important to figure out which adult roles to prepare for and commit to (Erikson, 1968). Previous findings showed that commitments became more strongly concurrently associated with depressive symptoms with age (Luyckx et al., 2013; Meeus et al., 1999). In both present studies, we found no age differences (i.e., no differences between cohorts, and no differences across measurement occasions) in the strength of commitments' predictive effects on depressive symptoms and stressful life events. This indicates that previously found age differences in the concurrent association cannot be explained by age differences in commitments' predictive effects.

\section{Strengths and Limitations}

A strength of the present research is the inclusion of two longitudinal studies spanning eight and six years. In Study 2, we were able to conceptually replicate several findings of Study 1 , such as the associations of stronger career commitments with relative decreases in stressful life events. Another strength is the inclusion of both the period of adolescence and 
young adulthood. Both periods are highly important for identity formation (Arnett, 2000; Erikson, 1968), and with our focus on both of them we have shown that weak identity commitments might be a risk for more negative experiences across both periods.

There were, however, also limitations that need to be acknowledged. First, the examined career and interpersonal commitments consisted of two more specific commitments: commitment to education and work and to a best friend and romantic partner. Both examined domains are salient for the majority of young people (Kroger, 1986; Skorikov \& Vondracek, 2011). However, within these broad domains the specific life stage appropriate commitments change during development, such as from education to work. Moreover, while for some young people education is still relevant, for another same-aged person this might already be work. By including two specific commitments within broader domains, it was possible to examine commitments' role across adolescence and young adulthood. Although the specific commitments within a domain are expected to be closely linked (Erikson, 1968; Negru-Subtirica et al., 2017), associations with depressive symptoms and stressful life events could differ between these more specific commitments.

Second, we have only investigated identity commitments, and no other dimensions through which these commitments are expected to be formed, like in-depth exploration and reconsideration (Crocetti et al., 2008). Extending the examination of the role of identity in depressive symptoms and stressful life events with these dimensions in future studies can indicate more clearly when identity is predictive (e.g., especially strong commitments that are not reconsidered predict less negative experiences), and how identity formation is affected (e.g., negative experiences might result in more reconsideration, resulting in weaker commitments).

Last, the present studies focused on the between-person level of analysis. Studies at the between-person level show which individuals are at risk for a relative increase. Such 
findings are of importance to detect particular subgroups of young people that are more at risk for experiencing higher levels of depressive symptoms or more stressful life events than their peers. However, our findings do, for example, not directly indicate that one individual with a weaker commitment will experience an increase in depressive symptoms in the following years at the within-person level (Hamaker, Kuiper, \& Grasman, 2015).

\section{Conclusion}

The findings of the present studies connect well with previous research that showed that strong identity commitments are associated with adolescents' and young adults' positive well-being. Moreover, the present studies contribute to the literature on the role of identity commitments in several ways. First, our findings indicate that commitments are predictive of negative experiences. Specifically, stronger interpersonal commitments predicted a relative decline in depressive symptoms across the next three years, and stronger career commitments were predictive of experiencing relatively fewer stressful life events. Second, our findings indicate that negative experiences more strongly predicted young people's career commitments than their interpersonal commitments. This difference could be caused by the importance of relationships during difficult times, because they might be a source of support. Therefore, young people that experience difficulties might still invest in maintaining strong interpersonal commitments, while their career commitments relatively weaken. Third, our findings did not show support for a buffering role of stronger identity commitments. Only having stronger interpersonal or career commitments does not seem to make young people more resilient to the negative impact of stressful life events. Young people's identity commitments are likely more directly linked to negative experiences. This study thereby underscores the importance of identity commitments in adolescence and young adulthood, and provides crucial nuances in the distinct links of career and interpersonal commitments with negative experiences. 


\section{References}

American Psychiatric Association. (2013). Diagnostic and statistical manual of mental disorders (5th ed.). Arlington, VA: American Psychiatric Publishing.

American Psychological Association. (2010). Ethical principles of psychologists and code of conduct. Retrieved from http://apa.org/ethics/code/index.aspx

Anthis, K. S. (2002). On the calamity theory of growth: The relationship between stressful life events and changes in identity over time. Identity, 2, 229-240. doi:10.1207/s1532706xid0203_03

Arnett, J. J. (2000). Emerging adulthood: A theory of development from the late teens through the twenties. American Psychologist, 55, 469-480. doi:10.1037/0003066x.55.5.469

Bollen, K. A. (2014). Structural equations with latent variables. New York, NY: Wiley.

Branje, S., Laninga-Wijnen, L., Yu, R., \& Meeus, W. (2014). Associations among school and friendship identity in adolescence and romantic relationships and work in emerging adulthood. Emerging Adulthood, 2, 6-16. doi:10.1177/2167696813515851

Brown, B. B. (2004). Adolescents' relationships with peers. In R. M. Lerner \& S. L. (Eds.), Handbook of adolescent psychology. Hoboken, NJ: Wiley.

Byrne, B. M. (2013). Structural equation modeling with Mplus: Basic concepts, applications, and programming. New York, NY: Routledge.

Caspi, A., Moffitt, T., Thornton, A., Freedman, D., Amell, J., Harrington, H., . . Silva, P. H. (1996). The Life History Calendar: A research and clinical assessment method for collecting retrospective event-history data. International Journal of Methods in Psychiatric Research, 6, 101-114. doi:10.1002/(SICI)1234988X(199607)6:23.3.CO;2-E

Chavez-Korell, S., \& Torres, L. (2014). Perceived stress and depressive symptoms among 
Latino adults: The moderating role of ethnic identity cluster patterns. The Counseling Psychologist, 42, 230-254. doi:10.1177/0011000013477905

Chen, F. F. (2007). Sensitivity of goodness of fit indexes to lack of measurement invariance. Structural Equation Modeling: A Multidisciplinary Journal, 14, 464-504. doi:10.1080/10705510701301834

Cheung, G. W., \& Rensvold, R. B. (2002). Evaluating goodness-of-fit indexes for testing measurement invariance. Structural Equation Modeling: A Multidisciplinary Journal, 9, 233-255. doi:10.1207/S15328007SEM0902_5

Clancy, S. M., \& Dollinger, S. J. (1993). Identity, self, and personality: I. Identity status and the five-factor model of personality. Journal of Research on Adolescence, 3, 227-245. doi:10.1207/s15327795jra0303_2

Cohen, G. L., \& Prinstein, M. J. (2006). Peer contagion of aggression and health risk behavior among adolescent males: An experimental investigation of effects on public conduct and private attitudes. Child Development, 77, 967-983. doi:10.1111/j.14678624.2006.00913.x

Cole, D. A., Nolen-Hoeksema, S., Girgus, J., \& Paul, G. (2006). Stress exposure and stress generation in child and adolescent depression: A latent trait-state-error approach to longitudinal analyses. Journal of Abnormal Psychology, 115, 40-51. doi:10.1037/0021-843X.115.1.40

Compas, B. E. (1987). Stress and life events during childhood and adolescence. Clinical Psychology Review, 7, 275-302. doi:10.1016/0272-7358(87)90037-7

Côté, J. E. (1996). Sociological perspectives on identity formation: The culture-identity link and identity capital. Journal of Adolescence, 19, 417-428. doi:10.1006/jado.1996.0040

Crocetti, E., Branje, S., Rubini, M., Koot, H. M., \& Meeus, W. (2017). Identity processes and 
parent-child and sibling relationships in adolescence: A five-wave multi-informant longitudinal study. Child Development, 88, 210-228. doi:10.1111/cdev.12547

Crocetti, E., Rubini, M., \& Meeus, W. (2008). Capturing the dynamics of identity formation in various ethnic groups: Development and validation of a three-dimensional model. Journal of Adolescence, 31, 207-222. doi:10.1016/j.adolescence.2007.09.002

Cumming, G. (2009). Inference by eye: Reading the overlap of independent confidence intervals. Statistics in Medicine, 28, 205-220. doi:10.1002/sim.3471

Ebata, A. T., \& Moos, R. H. (1991). Coping and adjustment in distressed and healthy adolescents. Journal of Applied Developmental Psychology, 12, 33-54. doi:10.1016/0193-3973(91)90029-4

Erikson, E. H. (1968). Identity: Youth and crisis. New York, NY: Norton.

Frankl, V. E. (1985). Man's search for meaning. New York, NY: Simon and Schuster.

Goldberg, D. P. (1978). Manual of the General Health Questionnaire. Horsham, United Kingdom: General Practice Research Unit.

Grotevant, H. D. (1987). Toward a process model of identity formation. Journal of Adolescent Research, 2, 203-222. doi:10.1177/074355488723003

Grotevant, H. D., \& Adams, G. R. (1984). Development of an objective measure to assess ego identity in adolescence: Validation and replication. Journal of Youth and Adolescence, 13, 419-438. doi:10.1007/BF02088639

Grotevant, H. D., Thorbecke, W., \& Meyer, M. L. (1982). An extension of Marcia's Identity Status Interview into the interpersonal domain. Journal of Youth and Adolescence, 11, 33-47. doi:10.1007/BF01537815

Hamaker, E. L., Kuiper, R. M., \& Grasman, R. P. P. P. (2015). A critique of the cross-lagged panel model. Psychological Methods, 20, 102-116. doi:10.1037/a0038889

Hankin, B. J., \& Abramson, L. Y. (2001). Development of gender differences in depression: 
An elaborated cognitive vulnerability-transactional stress theory. Psychological Bulletin, 127, 773-796. doi:10.1037//O033-29O9.127.6.773

Helsen, M., Vollebergh, W., \& Meeus, W. (1999). Psychosociale problemen in de adolescentie: De samenhang met hechting aan ouders en vrienden en identiteit. Nederlands Tijdschrift voor de Psychologie en haar Grensgebieden, 54, 256-275.

Holmes, T. H., \& Rahe, R. H. (1967). The social readjustment rating scale. Journal of Psychosomatic Research, 11, 213-218. doi:10.1016/0022-3999(67)90010-4

Holsen, I., \& Birkeland, M. S. (2017). Course, predictors, and outcomes of depressed mood in a cohort of norwegian adolescents followed from age 13 into adulthood age 30 . Emerging Adulthood, 5, 3-15. doi:10.1177/2167696816635810

Klimstra, T., \& Denissen, J. (in press). A theoretical framework for the associations between identity and psychopathology. Developmental Psychology.

Klimstra, T. A., Luyckx, K., Branje, S., Teppers, E., Goossens, L., \& Meeus, W. H. (2013). Personality traits, interpersonal identity, and relationship stability: Longitudinal linkages in late adolescence and young adulthood. Journal of Youth and Adolescence, 42, 1661-1673. doi:10.1007/s10964-012-9862-8

Koepke, S., \& Denissen, J. J. A. (2012). Dynamics of identity development and separationindividuation in parent-child relationships during adolescence and emerging adulthood: A conceptual integration. Developmental Review, 32, 67-88. doi:10.1016/j.dr.2012.01.001

Kovacs, M. (1985). The Children's Depression Inventory (CDI). Psychopharmacology Bulletin, 21, 995-998.

Kroger, J. (1986). The relative importance of identity status interview components: Replication and extension. Journal of Adolescence, 9, 337-354. doi:10.1016/s01401971(86)80040-9 
Kroger, J., \& Green, K. E. (1996). Events associated with identity status change. Journal of Adolescence, 19, 477-490. doi:10.1006/jado.1996.0045

Little, R. J. A. (1988). A test of missing completely at random for multivariate data with missing values. Journal of the American Statistical Association, 83, 1198-1202. doi:10.1080/01621459.1988.10478722

Liu, R. T., \& Alloy, L. B. (2010). Stress generation in depression: A systematic review of the empirical literature and recommendations for future study. Clinical Psychology Review, 30, 582-593. doi:10.1016/j.cpr.2010.04.010

Lüdtke, O., Roberts, B. W., Trautwein, U., \& Nagy, G. (2011). A random walk down university avenue: Life paths, life events, and personality trait change at the transition to university life. Journal of Personality and Social Psychology, 101, 620-637. doi:10.1037/a0023743

Luyckx, K., Goossens, L., Soenens, B., \& Beyers, W. (2006). Unpacking commitment and exploration: Preliminary validation of an integrative model of late adolescent identity formation. Journal of Adolescence, 29, 361-378. doi:10.1016/j.adolescence.2005.03.008

Luyckx, K., Klimstra, T. A., Duriez, B., Van Petegem, S., \& Beyers, W. (2013). Personal identity processes from adolescence through the late 20s: Age trends, functionality, and depressive symptoms. Social Development, 22, 701-721. doi:10.1111/sode.12027

Luyckx, K., Seiffge-Krenke, I., Schwartz, S. J., Goossens, L., Weets, I., Hendrieckx, C., \& Groven, C. (2008). Identity development, coping, and adjustment in emerging adults with a chronic illness: The sample case of type 1 diabetes. Journal of Adolescent Health, 43, 451-458. doi:10.1016/j.jadohealth.2008.04.005

Luyckx, K., Soenens, B., Goossens, L., \& Vansteenkiste, M. (2007). Parenting, identity formation, and college adjustment: A mediation model with longitudinal data. 
Identity, 7, 309-330. doi:10.1080/15283480701600785

Marcia, J. E. (1966). Development and validation of ego-identity status. Journal of Personality and Social Psychology, 3, 551-558. doi:10.1037/h0023281

Meeus, W. (1996). Studies on identity development in adolescence: An overview of research and some new data. Journal of Youth and Adolescence, 25, 569-598. doi:10.1007/bf01537355

Meeus, W. (2009). Life History Calendar, revised and adapted Dutch version. Unpublished manuscript, Adolescent Development, Utrecht University, Utrecht, the Netherlands.

Meeus, W. (2011). The study of adolescent identity formation 2000-2010: A review of longitudinal research. Journal of Research on Adolescence, 21, 75-94. doi:10.1111/j.1532-7795.2010.00716.x

Meeus, W. (2016). Adolescent psychosocial development: A review of longitudinal models and research. Developmental Psychology, 52, 1969-1993. doi:10.1037/dev0000243

Meeus, W., \& 't Hart, H. (1993). Jongeren in Nederland [Young people in the Netherlands]. Amersfoort, the Netherlands: Academische uitgeverij.

Meeus, W., Iedema, J., Helsen, M., \& Vollebergh, W. (1999). Patterns of adolescent identity development: Review of literature and longitudinal analysis. Developmental Review, 19, 419-461. doi:10.1006/drev.1999.0483

Meeus, W., Van de Schoot, R., Keijsers, L., Schwartz, S. J., \& Branje, S. (2010). On the progression and stability of adolescent identity formation: A five-wave longitudinal study in early-to-middle and middle-to-late adolescence. Child Development, 81, 1565-1581. doi:10.1111/j.1467-8624.2010.01492.x

Mueller, D. P., Edwards, D. W., \& Yarvis, R. M. (1977). Stressful life events and psychiatric symptomatology: Change or undesirability? Journal of Health and Social Behavior, 18, 307-317. doi:10.2307/2136356 
Muthén, L. K., \& Muthén, B. O. (1998-2015). Mplus User’s Guide. Seventh Edition. Los Angeles, CA: Muthén \& Muthén.

Negru-Subtirica, O., Pop, E. I., \& Crocetti, E. (2017). Good omens? The intricate relations between educational and vocational identity in adolescence. European Journal of Developmental Psychology, 1-16. doi:10.1080/17405629.2017.1313160

Negru-Subtirica, O., Pop, E. I., Luyckx, K., Dezutter, J., \& Steger, M. F. (2016). The meaningful identity: A longitudinal look at the interplay between identity and meaning in life in adolescence. Developmental Psychology, 52, 1926-1936. doi:10.1037/dev0000176

Pine, D. S., Cohen, P., Johnson, J., \& Brook, J. S. (2002). Adolescent life events as predictors of adult depression. Journal of Affective Disorders, 68, 49-57. doi:10.1016/S01650327(00)00331-1

Raphael, K. G., Cloitre, M., \& Dohrenwend, B. P. (1991). Problems of recall and misclassification with checklist methods of measuring stressful life events. Health Psychology, 10, 62-74. doi:10.1037/0278-6133.10.1.62

Roberts, B. W., O'Donnell, M., \& Robins, R. W. (2004). Goal and personality trait development in emerging adulthood. Journal of Personality and Social Psychology, 87, 541-550. doi:10.1037/0022-3514.87.4.541

Roelofs, J., Braet, C., Rood, L., Timbremont, B., van Vlierberghe, L., Goossens, L., \& van Breukelen, G. (2010). Norms and screening utility of the Dutch version of the Children's Depression Inventory in clinical and nonclinical youths. Psychological Assessment, 22, 866-877. doi:10.1037/a0020593

Schwartz, S. J., Beyers, W., Luyckx, K., Soenens, B., Zamboanga, B. L., Forthun, L. F., . . . Waterman, A. S. (2011). Examining the light and dark sides of emerging adults' identity: A study of identity status differences in positive and negative psychosocial 
functioning. Journal of Youth and Adolescence, 40, 839-859. doi:10.1007/s10964010-9606-6

Schwartz, S. J., Klimstra, T. A., Luyckx, K., Hale, W. W., 3rd, \& Meeus, W. H. (2012). Characterizing the self-system over time in adolescence: Internal structure and associations with internalizing symptoms. Journal of Youth and Adolescence, 41, 1208-1225. doi:10.1007/s10964-012-9751-1

Skorikov, V. B., \& Vondracek, F. W. (2011). Occupational identity. In S. J. Schwartz, K. Luyckx, \& V. L. Vignoles (Eds.), Handbook of identity theory and research (pp. 693714). New York, NY: Springer.

Swearingen, E. M., \& Cohen, L. H. (1985). Measurement of adolescents' life events: The junior high life experiences survey. American Journal of Community Psychology, 13, 69-85. doi:10.1007/BF00923260

't Hart, H. (1992). Opzet en uitvoering van het WIL-panel 1 en 2 [Design and data-collection of the Utrecht Study of Adolescent Development 1 and 2]. Unpublished manuscript, Utrecht University, the Netherlands.

Thoits, P. A. (1983). Multiple identities and psychological well-being: A reformulation and test of the social isolation hypothesis. American Sociological Review, 48, 174-187. doi: $10.2307 / 2095103$

Updegraff, J. A., \& Taylor, S. E. (2000). From vulnerability to growth: Positive and negative effects of stressful life events. In J. Harvey \& E. Miller (Eds.), Loss and trauma: General and close relationship perspectives (pp. 3-28). Philadelphia, PA: BrunnerRoutledge.

Van Doeselaar, L., Meeus, W., Koot, H. M., \& Branje, S. (2016). The role of best friends in educational identity formation in adolescence. Journal of Adolescence, 47, 28-37. doi:10.1016/j.adolescence.2015.12.002 


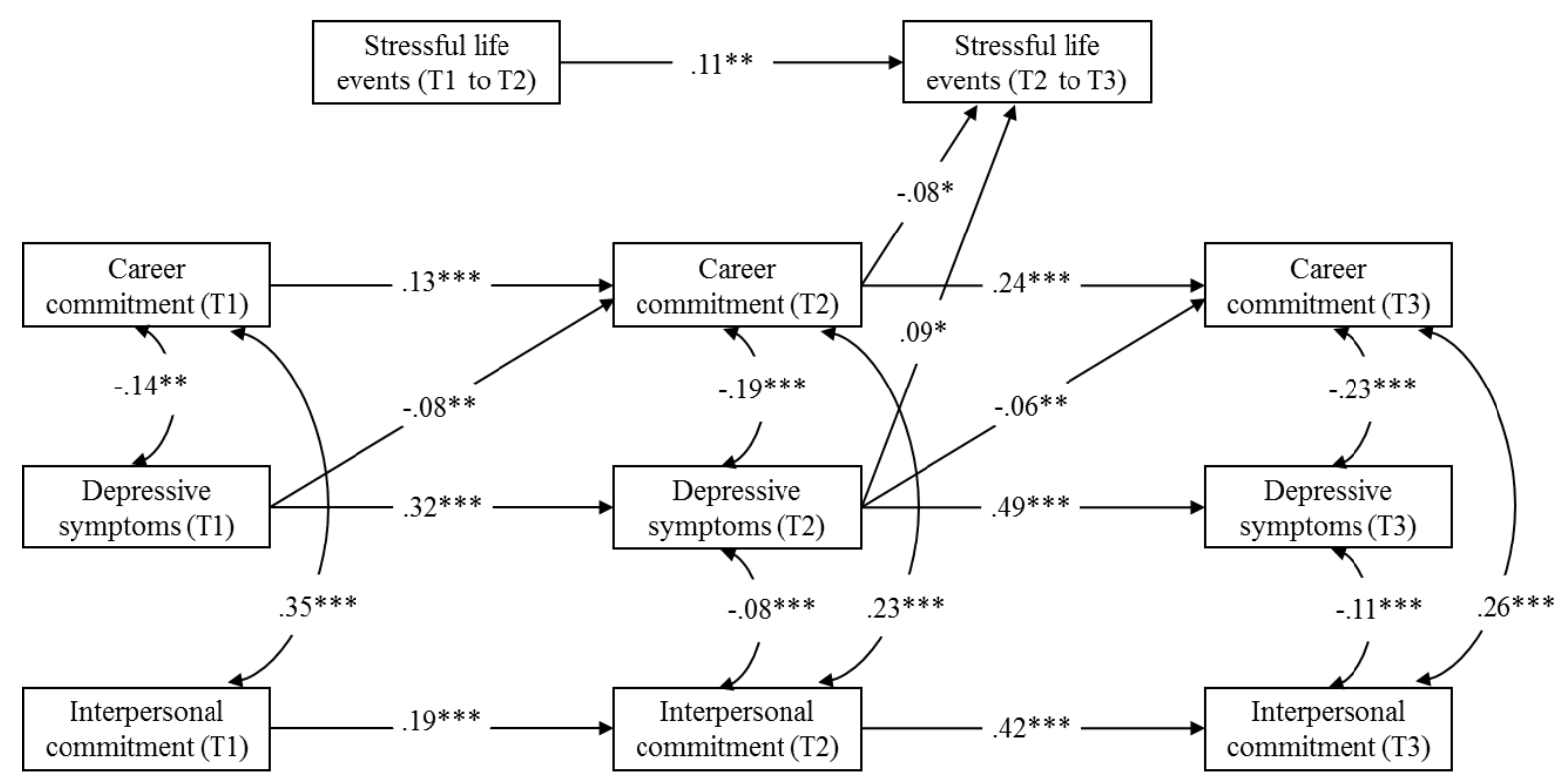

Figure 1. Standardized estimates of the model analyzed in Study 1. For reasons of clarity, cross-lagged effects, correlations, and interaction effects that were not significant are not shown. 
$\underline{\mathrm{T}}$

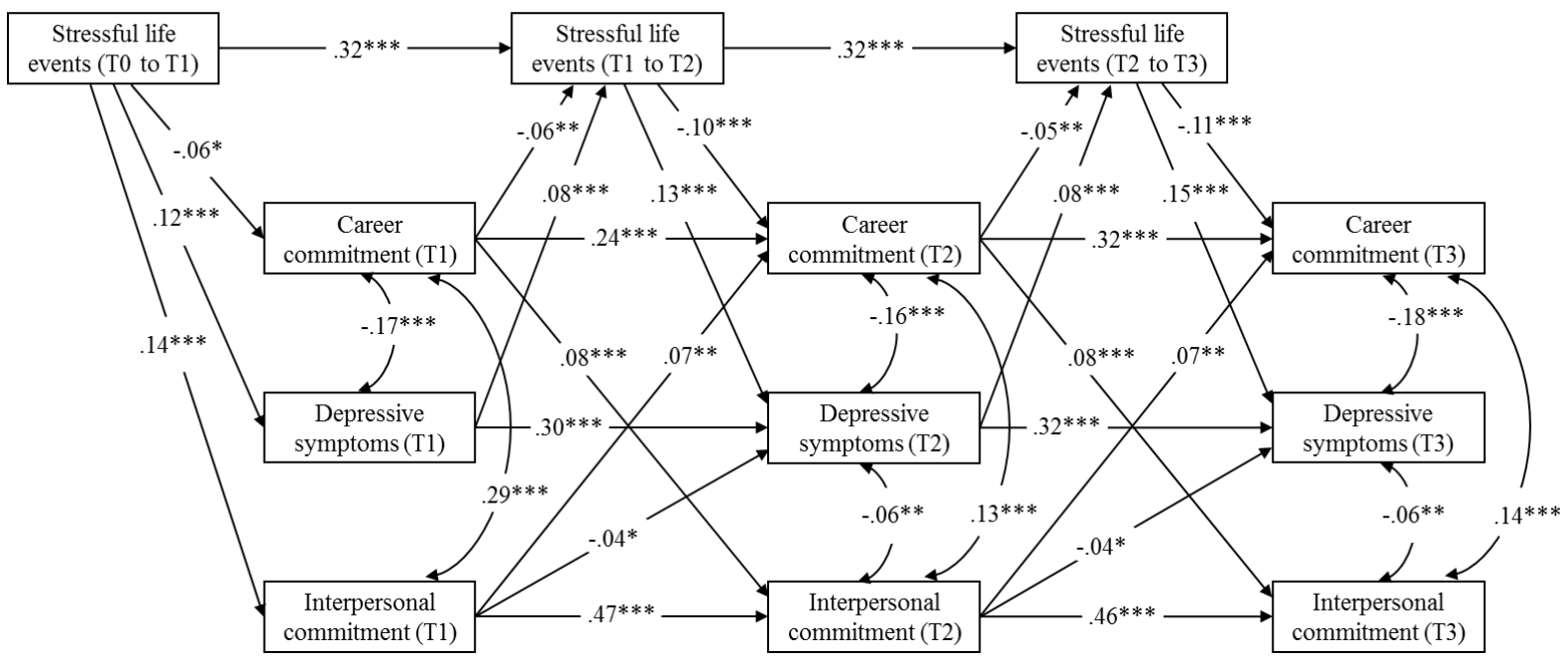

Figure 2. Standardized estimates of the model analyzed in Study 2. For reasons of clarity, cross-lagged effects, correlations, and interaction effects that were not significant are not shown. 